\title{
VANTAGEM COMPETITIVA: os modelos teóricos atuais e a convergência entre estratégia e teoria organizacional
}

Flávio C. Vasconcelos

DEA em Sociologia pelo Institut d'Etudes Politiques de Paris, Docteur ès Sciences de Gestion pela Ecole des Hautes Etudes Commerciales (Paris) e Professor do Departamento de Administração Geral e Recursos Humanos da EAESP/FGV. E-mail: fvasconcelos@fgvsp.br

\section{Álvaro B. Cyrino}

DEA em Gestão da Tecnologia pela Université Tecnologique de Compiègne, Doutorando em Administração na Ecole des Hautes Etudes Commerciales (Paris) e Gerente de Projetos da Fundação Dom Cabral.

E-mail: abcyrino@fdc.org.br

\section{RESUMO}

Este artigo faz uma análise das quatro principais correntes teóricas que tratam do fenômeno da vantagem competitiva, isto é, a ocorrência de níveis de performance econômica acima da média de mercado em função das estratégias adotadas pelas firmas. São examinadas, em termos de seus pressupostos e de suas conseqüências, as teorias de posicionamento estratégico, a teoria dos recursos, as teorias baseadas nos processos de mercado e as teorias de competências dinâmicas. Finalmente, este artigo defende a tese de uma convergência entre estratégia empresarial e teoria organizacional como uma via de pesquisa fundamental para a evolução de ambas as disciplinas.

\section{ABSTRACT}

This article analyzes the convergence between business strategy and organizational theory, by making a detailed comparative study of four theories focusing competitive advantage phenomena. These theories include the strategic positioning school, the resource-based view, the market processes and the dynamic competencies theory. We conclude the convergence between organizational theory and business strategy is a promising research opportunity for both disciplines.

PALAVRAS-CHAVE

Estratégia empresarial, teoria organizacional, posicionamento estratégico, teoria dos recursos, competências.

Business policy, organizational theory, strategic positioning, resource-based view, competencies. 


\section{UMA TENDÊNCIA DE CONVERGÊNCIA}

Dois temas fundamentais estruturam a evolução recente do pensamento sobre estratégia empresarial: a vantagem competitiva e a mudança organizacional e estratégica. Embora distantes nas suas origens, tendo seguido por vários anos trajetórias paralelas, esses dois tópicos tendem a convergir progressivamente em função das rápidas mudanças econômicas e sociais que caracterizam a economia mundial na virada do século XXI.

Uma série de contribuições teóricas e conceituais, tanto no campo da Administração Estratégica como no campo da Teoria das Organizações, levou a essa convergência: no campo da Estratégia Empresarial, os trabalhos de pesquisa costumam basear-se em fundamentos econômicos, focalizando o "conteúdo" das estratégias. Esses trabalhos normalmente utilizam abordagens metodológicas estruturadas dirigidas à verificação empírica de hipóteses generalizáveis. Também é comum que tais estudos concedam uma especial importância às implicações normativas dos resultados. Seu objetivo principal costuma ser identificar os fatores responsáveis pelo sucesso ou fracasso das empresas em diferentes contextos.

Um segundo grupo de contribuições embasa-se nas Ciências Sociais em geral e na Sociologia em particular. Essas contribuições focalizam-se sobre a natureza da mudança organizacional e os processos internos de adaptação, inovação e aprendizagem, utilizando, preferencialmente, métodos qualitativos com o objetivo de entender e explicar, no seu contexto, a natureza e a dinâmica dos processos de mudança organizacional.

No entanto, apesar das consideráveis diferenças teóricas e metodológicas, diversas razões justificam a convergência dessas duas correntes. Primeiramente, a evolução dos ambientes organizacionais, cada vez mais marcados pela evolução tecnológica, pela interconexão entre grandes redes de organizações e pela integração dos mercados mundiais. Altos níveis de incerteza e ambigüidade ambiental contribuem fortemente para que a mudança organizacional seja vista não como um evento raro, mas como uma ocorrência cada vez mais freqüente nas organizações. A importância da mudança organizacional é, assim, posta em evidência pela percepção generalizada de que a mudança é essencialmente inevitável. Daí surge uma forte motivação para compreender e influenciar os processos de mudança organizacional, estabelecendo uma interface entre a estratégia como fenômeno intencional e o comportamento organizacional como fenômeno emergente. Essa aproximação implica, finalmente, dar um aspecto mais normativo aos estudos sobre mudança organizacional.

Em segundo lugar, a ausência de estabilidade e previsibilidade coloca em evidência as fraquezas de uma grande parte dos modelos utilizados em Administração Estratégica, primeiramente, no plano prático e, em seguida, no plano teórico. A decadência do planejamento estratégico, analisada por Mintzberg (1994), pode ser vista, nesse sentido, como um sinal

\section{A estrutura da indústria determina 0}

\section{comportamento dos agentes econômicos, que determina a performance das firmas.}

da inadequação dos modelos de Estratégia Empresarial às características do mundo real. Para a disciplina de Administração Estratégica, que, tradicionalmente, visa a informar e orientar a prática, a rejeição dos principais modelos de planejamento estratégico fez soar um alarme, apontando para a necessidade da redefinição de seu escopo e de sua inter-relação com outras disciplinas, levando, em última instância, a uma aproximação entre a fundamentação econômica e a descrição sociológica.

As análises dos modelos teóricos e das contribuições empíricas feitas neste artigo visam a evidenciar as duas dimensões responsáveis pela convergência acima citada:

a) o reconhecimento do aumento da complexidade ambiental e de seus impactos sobre o comportamento das firmas;

b) o foco nos processos e recursos intra-organizacionais.

\section{A TEORIA ECONÔMICA NEOCLÁSSICA E SEUS LIMITES}

Até os anos 70, a explicação ortodoxa sobre o comportamento econômico das organizações encontrava-se predominantemente na economia neoclássica de inspiração walrasiana. A firma neoclássica, no entanto, revelava-se uma simplificação demasiadamente grosseira para definir o comportamento real das empresas, o que explica a ausência de aplicações da análise econômica clássica nas empresas e o seu papel secundário nos trabalhos de estratégia empresarial. 
Na realidade, na concepção econômica neoclássica, a vantagem competitiva - resultados consistentemente superiores à média - é um epifenômeno: seja um acidente excepcional, seja uma imperfeição temporária do funcionamento dos mercados. O poder das forças de concorrência, dirigido pela mão invisível dos mercados, tende a corroer todo lucro acima da média por meio de mecanismos de fluxo livre de capitais à procura da máxima lucratividade.

\section{0 processo competitivo é caracterizado por}

\section{um processo interativo de descoberta, no qual novos conhecimentos são produzidos.}

res obstáculos à aplicabilidade estratégica dos modelos de análise econômica: “(...) The notion that a firm can choose from a finite set of strategies (...) implies that a firm's resources and capabilities are not completely fungible and generalizable, certainly in the short run, if not in the long run. Particular strategies imply particular investment decisions, organizational structures, and possibly particular organizational cultures. Put it differently, the concept implies that certain factors of production are semi permanently tied to the firm by recontracting costs and, perhaps, market imperfections (...)" (Teece, 1984, p. 88).

Uma parte importante da estratégia empresarial focaliza-se justamente no longo prazo, em que as características dinâmicas, as inter-relações

Além disso, falta à microeconomia ortodoxa uma teoria da firma como fenômeno coletivo. A firma não é tratada como uma instituição, mas como um ator individual, sem nenhuma autonomia de decisão que responda racionalmente (e passivamente) às mudanças no ambiente (reduzido, na concepção clássica, aos mecanismos de preços e quantidades).

Assim, a firma “(...) se présente comme un agent sans épaisseur ni dimension, une 'firme point'; et comme un agent passif, la 'firme automate' (...)" (Coriat e Weinstein, 1995, p. 14).

A firma é, então, dotada do mesmo estatuto teórico do consumidor individual, que apenas aplica mecanicamente as regras do cálculo econômico e é representado em termos de uma função de transformação de insumos em produtos. Teece assim resumiu esses limites da firma: “(...) With little exaggeration, we can assert that, until very recently, economics lacked a theory of the firm. (...) one finds a theory of production masquerading as a theory of the firm. Firms are typically represented as production functions, or, in some formulations, production sets. The (neoclassic) firm is a 'black box' which transforms the factors of production into usually just one output" (Teece, 1984, p. 90).

A teoria econômica neoclássica é baseada em premissas de equilíbrio, certeza e racionalidade perfeita que resultam em um tipo de análise estática do processo de tomada de decisão, focalizando a maximização da função objetivo (utilidade) em um momento específico, dados os processos tecnológicos e o preço dos fatores e dos produtos. Os limites práticos à conversão de recursos, a especificidade de ativos, as particularidades tecnológicas e o conceito de interação organizacional não têm nenhum espaço nesse modelo. Esses problemas representam, segundo Teece, um dos maio- entre as decisões, a mudança e a incerteza devem ser tratadas como fenômenos essenciais, e não como imperfeições capazes de ameaçar a elegância matemática dos modelos econométricos. Assim, a própria noção de estratégia é estranha aos preceitos da economia neoclássica, em que as decisões das firmas se concentram na alocação de recursos fungíveis entre alternativas finitas e conhecidas. A tecnologia e o knowhow são dados, e sua difusão faz-se de uma maneira perfeitamente fluida. Nesse sentido, as idéias de estratégia, antecipação e planejamento são desnecessárias e, até mesmo, disfuncionais.

\section{A QUESTÃO DA VANTAGEM COMPETITIVA}

A partir dos anos 70, diversas correntes do pensamento econômico abordaram a questão da vantagem competitiva utilizando abordagens conceituais diferentes. Algumas das correntes contemporâneas não colocam verdadeiramente a questão das estratégias empresariais no centro de suas preocupações. É o caso, como vimos anteriormente, da economia neoclássica, das abordagens contratuais da firma (da economia de custos de transação e da teoria da agência).

As teorias de Estratégia Empresarial que tratam da questão da vantagem competitiva podem ser divididas em dois eixos principais. O primeiro eixo classifica os estudos segundo sua concepção da origem da vantagem competitiva. Dois casos são, assim, identificados: a) as teorias que consideram a vantagem competitiva como um atributo de posicionamento, exterior à organização, derivado da estrutura da indústria, da dinâmica da concorrência e do mercado e b) as que consideram a performance superior como um fenômeno decorrente primariamente de características internas da organização. 
A segunda dimensão discrimina as abordagens segundo suas premissas sobre a concorrência. Uma divisão se faz entre os pesquisadores que possuem uma visão estrutural, essencialmente estática, da concorrência, fundada na noção de equilíbrio econômico, e os que enfocam os aspectos dinâmicos e mutáveis da concorrência, acentuando fenômenos como inovação, descontinuidade e desequilíbrio.

As teorias de Estratégia Empresarial podem ser representadas seguindo essas duas dimensões, como mostra a Figura 1.

\section{A ESTRUTURA DA INDÚSTRIA: DEFININDO O CENÁRIO DA CONCORRÊNCIA}

Um dos modelos conceituais mais difundidos para a análise da vantagem competitiva é o modelo da nova organização industrial (new industrial organization). Esse conjunto de idéias apóia-se nos trabalhos pioneiros de Edward Mason e Joe Bain sobre a estrutura da indústria, um modelo que ficou conhecido como análise SCP (Structure-Conduct-Performance) ou EstruturaComportamento-Performance. De acordo com essa tendência, a performance das firmas em uma indústria particular depende do comportamento (estratégia) de compradores e vendedores no tocante a fixação de preços, níveis de cooperação tácita e competição, políticas de pesquisa e desenvolvimento, publicidade, investimento, etc. O comportamento das firmas é, por sua vez, definido pela estrutura da indústria em questão, caracteri- zada pelo número e pelo tamanho relativo de concorrentes, compradores e vendedores, pelo grau de diferenciação dos produtos, pela existência de barreiras de entrada de novas firmas, pelo grau de integração vertical existente, etc. Em resumo, o modelo SCP supõe que a performance econômica das firmas é o resultado direto de seu comportamento concorrencial em termos de fixação de preços e custos e que esse comportamento depende da estrutura da indústria na qual as firmas estão inseridas.

Devemos notar que os trabalhos de Mason e Bain visavam a explicar e analisar a lucratividade dos oligopólios com o objetivo de implantar políticas de promoção da concorrência (anti-trust). Para esses dois pesquisadores, o poder dos monopólios e dos oligopólios representavam uma ameaça à sociedade e ao seu equilíbrio econômico. Trabalhos neo-estruturalistas, como os desenvolvidos por Michael Porter, utilizaram o modelo básico de Mason e Bain para a formulação de estratégias de empresas utilizando o poder dos monopólios em favor das empresas, e não numa perspectiva de regulamentação governamental, como fizeram anteriormente Mason e Bain. O papel determinante da estrutura industrial é um tema recorrente entre os pesquisadores dessa corrente. Influenciados pela noção simplificada de firma "pontual" inspirada nos modelos neoclássicos, os pesquisadores da economia industrial tendem a ignorar os aspectos organizacionais da estratégia empresarial. Segundo Bain: “(...) I am concerned with the

Figura 1 - As correntes explicativas da vantagem competitiva

A vantagem competitiva explica-se por fatores externos (mercados, estrutura das indústrias).

A vantagem competitiva explica-se por fatores internos específicos à firma.

\begin{tabular}{|c|c|}
\hline $\begin{array}{c}\text { 1 - Análise estrutural da indústria } \\
\text { Organização industrial: Modelo SCP } \\
\text { Análise de Posicionamento } \\
\text { (Porter) }\end{array}$ & $\begin{array}{c}\text { Escola Austríaca } \\
\text { (Hayek, Schumpeter) }\end{array}$ \\
\hline 2 - Recursos e competências & $4-$ Capacidades dinâmicas \\
Teoria dos Recursos & Teoria das Capacidades Dinâmicas \\
\hline Estrutura da indústria & \\
\hline Estática: equilíbrio e estrutura & Processos de mercado \\
(market process) \\
Dinâmica: mudança e incerteza
\end{tabular}


environmental setting within enterprises operate and in how they behave in these settings as producers, sellers and buyers. By contrast, I do not take an internal approach, more appropriate to the field of management science, such as could inquire how enterprises do and should behave in ordering their internal operations and would attempt to instruct them accordingly (...) my primary unit of analysis is the industry of competing group of firms, rather than the individual firm or the economy wide aggregate of enterprises (...)" (Bain, 1959, p. VII-VIII, citado por Foss, 1996).

A análise inicial de Porter sobre a vantagem competitiva acentua alguns elementos característicos da nova organização industrial. Em primeiro lugar, Porter compartilha com o modelo de Mason e Bain a mesma unidade de análise, a indústria, e não a firma individual: "The basic unit of analysis in a theory of strategy must ultimately be a strategically distinct business or industry" (Porter, 1991, p. 99).

Em segundo lugar, a lógica dos modelos de organização industrial é muito clara sobre as origens e o sentido de causalidade do modelo, começando pela estrutura da indústria que determina o comportamento dos agentes econômicos, que determina a performance das firmas. Ainda que outros elementos sejam ocasionalmente considerados, o posicionamento da firma dentro da estrutura industrial é, segundo Porter, o principal determinante de seu sucesso ou fracasso no cenário competitivo.

“(...) At the broadest level, firm success is a function of two areas: the attractiveness of the industry in which the firm competes and its relative position in that industry. Firm profitability can be decomposed into an industry effect and a positioning effect. Some firm successes come almost wholly from the industry in which they compete; most of their rivals are successful too! (...)" (Porter, 1991, p. 100).

No seu segundo livro, Porter inclui um elo adicional na explicação do sucesso competitivo, explorando os conceitos de atividades e fatores determinantes. As atividades ali analisadas constituem as "unidades básicas de análise de uma firma", e sua configuração particular determina a estratégia da empresa. A vantagem competitiva é, assim, o resultado da capacidade da firma de realizar eficientemente o conjunto de atividades necessárias para obter um custo mais baixo que o dos concorrentes ou de organizar essas atividades de uma forma única, capaz de gerar um valor diferenciado para os compradores. Segundo Porter, apenas dois fatores determinam a vantagem competitiva: as condições iniciais e a escolha dos dirigentes. As condições iniciais representam os ativos acumulados pela empresa no decorrer do tempo, geralmente derivados de sua relação com o ambiente externo imediato (ambiente transacional). A estratégia, nesse modelo, consiste em posicionar a empresa dentro do seu ambiente e, especialmente, da sua indústria. O papel reservado à estratégia, nesse sentido, é proteger a firma da ação das forças competitivas. Segundo Porter: “(...) The goal of competitive strategy for a business unit in an industry is to find a position in the industry where the company can best defend itself against these competitive forces or can influence them in its favor (...)" (Porter, 1980, p. 4).

A principal maneira de chegar a essa posição protegida é construir barreiras à entrada de outras firmas na indústria em questão para impedir a erosão das margens de lucratividade, o que implica, em geral, estabelecer mecanismos de acordo tácito entre os atores econômicos na indústria. Dessa maneira, as indústrias consideradas mais atraentes pelos pesquisadores da economia industrial são as situações que se aproximam dos monopólios e oligopólios.

A noção de estratégia é, assim, fortemente orientada em direção à noção de adaptação (fit). Em primeiro lugar, há a noção de adaptação externa implícita na lógica do posicionamento da firma na indústria. É a partir da análise objetiva de seu ambiente que a firma será capaz de identificar a posição mais favorável. A escolha da estratégia correta permitirá à firma adaptar-se à estrutura da indústria. Em segundo lugar, a estratégia deve ser internamente coerente, adaptando os elementos internos da firma à sua posição na indústria. As atividades da firma devem, dessa maneira, ser configuradas de maneira coerente, cada uma dando suporte e complementando a outra. É essa sinergia e coerência interna que tornam possível a execução de uma estratégia bem-sucedida (Porter, 1991, 1996).

Outras abordagens derivadas das idéias da organização industrial surgiram recentemente na literatura sobre estratégia. A primeira dessas abordagens estrutura-se em torno da idéia de concorrência engajada (commited competition), identificando a vantagem competitiva sustentável em função de decisões de investimento irreversíveis que sinalizam o fechamento de oportunidades de mercado ou de acesso a recursos, condicionando a tomada de outras decisões. Os engajamentos estratégicos sinalizam aos concorrentes a disposição da firma em lutar por um certo mercado, ainda que baixando radicalmente sua rentabilidade, funcionando como fatores dissuasivos de novos entrantes potenciais (Ghemawat, 1986, 1991). 
Uma segunda contribuição deriva da teoria dos jogos aplicada à modelização do comportamento das firmas a partir das variáveis estruturais da indústria, tentando dar uma dimensão mais dinâmica à estratégia (Shapiro, 1989). A correspondência dos modelos ao comportamento real das empresas depende, no entanto, das premissas utilizadas para a construção da estrutura do jogo. As idéias da organização industrial têm uma influência decisiva nesse sentido. As estruturas do modelo devem traduzir um conjunto de premissas compartilhadas pelos atores, de forma que se possa estruturar um "jogo" entre eles. Por essa razão, a teoria dos jogos foi mais bem-sucedida em explicar o comportamento de indústrias maduras e estáveis, nas quais as estratégias dos atores são simétricas e não existem descontinuidades freqüentes na relação de forças entre os competidores.

Porter articulou o primeiro e provavelmente o mais influente "paradigma" no campo da Estratégia Empresarial, o que explica a importante difusão de suas idéias nos últimos 25 anos. Porter oferece a promessa de uma explicação fundada sobre uma estrutura teórica consistente e empiricamente verificável, capaz de prever o comportamento das empresas em muitos casos reais. Alguns aspectos críticos, no entanto, fazem-se notar. Em primeiro lugar, os processos intra-organizacionais têm um papel secundário nos trabalhos da escola de organização industrial. Sendo a indústria a unidade de análise, a firma é vista apenas como um conjunto de atividades organizadas. As diferenças entre as firmas são reduzidas a diferenças de tamanho e posicionamento, sem maiores considerações sobre o que acontece no interior das fronteiras organizacionais. Fortes premissas de racionalidade econômica também estão embutidas nessa corrente de comportamento das firmas. As teorias da economia industrial adotam um modelo de racionalidade próximo ao da economia neoclássica. Os dirigentes são capazes de analisar completa e objetivamente todos os aspectos relevantes da indústria e formular estratégias otimizadas para eles. A estratégia é, nessa perspectiva, uma escolha de otimização entre tipos gerais de combinações entre produtos e mercados (liderança de custos, diferenciação e focalização).

O caráter exógeno e determinante das forças externas em relação à dinâmica interna da firma transforma a estratégia em um esforço contínuo de adaptação ex post, uma série de conformações sucessivas a forças externas incontroláveis.

\section{RECURSOS E COMPETÊNCIAS: DESCOBRINDO AS ESPECIFICIDADES DAS ORGANIZAÇÕES}

O conjunto de idéias que se convencionou chamar de teoria dos recursos aparece durante os anos 80 como uma alternativa à posição dominante da organização industrial.

A proposição central dessa corrente é que a fonte da vantagem competitiva se encontra primariamente nos recursos e nas competências desenvolvidos e controlados pelas empresas e apenas secundariamente na estrutura das indústrias nas quais elas se posicionam.

\section{0 enfoque privilegiado nos processos organizacionais} permite a criação de uma teoria estratégica mais
flexível do que as visões economicistas.

As firmas são, assim, consideradas como "feixes de recursos" (Wernerfelt, 1984) ou como conjuntos de competências e capacidades (Prahalad e Hamel, 1990). Esses recursos e capacidades são vistos como elementos raros, de imitação e substituição difícil e custosa no quadro de uma organização particular (Barney, 1991, 1997). A idéia de recursos inclui não apenas recursos físicos e financeiros mas também recursos intangíveis (Hall, 1992) ou invisíveis (Itami e Roehl, 1987).

A origem recente da teoria dos recursos é normalmente associada ao trabalho de Wernerfelt (1984). No entanto, diversas contribuições teóricas mais antigas abriram caminho para a constituição da teoria dos recursos. Entre essas contribuições, encontramos a obra de Philip Selznick, que, a partir dos seus estudos sobre a TVA e os partidos bolchevistas, foi um dos primeiros a caracterizar as organizações como entidades que constroem recursos específicos por meio do processo de institucionalização, um processo no qual a organização passa de um instrumento à materialização de um conjunto específico de valores. Selznick mostra que as organizações, por meio das escolhas estratégicas que fazem, adquirem um caráter individual: "(...) The formation of an institution is marked by the making of value commitments, that is, choices which fix the assumptions of policymakers as to the nature of the enterprise - its distinctive aims, methods, and role in the community. These 
character defining choices are not made verbally; they may not even be made consciously. When such commitments are made, the values in question are actually built into the social structure (...)" (Selznick, 1957, p. 55-56).

Os trabalhos da economista Edith Penrose também exerceram uma influência decisiva na formação da teoria dos recursos. Essa pesquisadora foi uma das primeiras a conceber a firma como um "feixe de recursos", antecipando, dessa forma, um dos conceitos básicos da teoria dos recursos. Penrose concentrou-se sobre a questão do crescimento das empresas, adotando uma perspectiva que se diferenciava daquela defendida pelos economistas neoclássicos. Para ela, a firma se definia como uma entidade administrativa e um conjunto de recursos, e não como uma função abstrata de transformação de insumos em produtos.

A idéia de recursos no lugar do conceito clássico de fatores de produção representa uma significativa mudança: “(...) Une entreprise est donc quelque chose de plus qu'une unité administrative; elle est également un ensemble de facteurs de production, dont l'utilisation pour différents usages et dans le cours du temps est déterminée par une décision administrative. Si nous considérons la fonction de l'entreprise privée sous cet angle, le meilleur moyen d'évaluer les dimensions d'une entreprise est de trouver une mesure des facteurs de production qu'elle utilize (...)" (Penrose, 1959/1963, p. 31).

Os processos de expansão das firmas são, dessa maneira, caracterizados tanto pelas oportunidades externas como pelas internas derivadas do conjunto de recursos da firma. A ênfase de Penrose recai sobre os limites e as possibilidades que os recursos internos colocam à expansão das firmas.

Esse reconhecimento da heterogeneidade implica a valorização do processo de aprendizagem interna da organização: “(...) d'apprendre à mieux connaître les facteurs de production avec lesquels ils travaillent, et qu'une meilleure connaissance a des chances d'augmenter la rentabilité et la productivité de leur entreprises (...) (en orientant) la recherche soit sur les caractéristiques propres de ce facteur, soit sur les façons de combiner ses caractéristiques avec celles d'autres facteurs de production (...)" (Penrose, 1959/1963, p. 75).

Dessa forma, é a procura constante da utilização plena dos recursos que impede o equilíbrio das firmas e dos mercados. Mesmo se as condições da indústria e da concorrência forem estáveis, cada firma, tentando otimizar o uso do seu "feixe de recursos", se afastaria do equilíbrio. Penrose, assim, antecipa a descoberta de muitos temas centrais da teoria dos recursos, como a especificidade das firmas, a heterogeneidade dos recursos, a importância do conhecimento sobre eles e seus possíveis usos.

Um outro grupo de precursores da teoria dos recursos é composto pelos proponentes da escola de design estratégico (Andrews, 1980). O modelo de análise SWOT (forças e fraquezas, oportunidades e ameaças) supõe alguns dos conceitos básicos da teoria dos recursos na medida em que a análise de forças e fraquezas se baseia em uma análise interna (focada em recursos e competências distintivas) e a análise de oportunidades e ameaças se baseia em uma análise externa (focada nas condições de concorrência e demanda). Em geral, as forças e fraquezas de uma organização são resultado: a) das forças e fraquezas dos indivíduos que compõem a organização; b) da forma como essas capacidades individuais são integradas no trabalho coletivo e c) da qualidade da coordenação dos esforços de equipe (Andrews, 1980). Essa análise aproxima-se bastante da visão proposta pela teoria dos recursos, isto é, que a competitividade de uma organização se fundamenta essencialmente em sua capacidade de selecionar e combinar recursos adequados e mutuamente complementares.

A teoria dos recursos, em sua forma atual, fundamenta-se em duas generalizações empíricas e dois postulados (Foss, 1997).

As generalizações empíricas são:

a) Há diferenças sistemáticas entre as firmas no tocante à forma com que elas controlam os recursos necessários à implementação de suas estratégias.

b) Essas diferenças são relativamente estáveis.

Os postulados são:

a) As diferenças nas dotações de recursos causam diferenças de performance.

b) As firmas procuram constantemente melhorar sua performance econômica.

A primeira constatação empírica, sobre as diferenças sistemáticas das dotações de recursos, entra em conflito com a teoria econômica tradicional, que vê as diferenças entre firmas como, na melhor das hipóteses, o resultado de diferenças particulares devidas ao acaso (Nelson, 1991). Além do mais, na maior parte das visões ortodoxas da firma, as diferenças são apenas diferenças de escala, sem a consideração efetiva das diferenças qualitativas. A estabilidade das diferenças contradiz também o postulado do equilíbrio geral do sistema econômico, que pressupõe que os mecanismos de mercado e da concorrência tendem a anular todas as diferenças no decorrer do tempo. A idéia de que as diferenças qualitativas das firmas possam ser atribuídas a recursos 
específicos representa também uma ruptura com as teorias focalizadas na estrutura da indústria (Mason, Bain, Porter), que atribuem a diferença entre as firmas a fatores externos, como seu posicionamento dentro da indústria. Duas conseqüências importantes derivam desse postulado: primeiramente, para justificar as diferenças de performance, os recursos devem ser capazes de gerar produtos ou serviços comercializáveis (Collis, 1996). Não é o bastante que as firmas tenham recursos distintos. O que diferencia os recursos, na realidade, é sua capacidade de gerar valor para os clientes (Hamel, 1995) ou a sua capacidade de permitir a implantação de estratégias diferenciadas (Barney, 1997).

Esse raciocínio leva a uma mudança fundamental da visão sobre a natureza da concorrência, que, em lugar de ser uma concorrência entre produtos, passa a ser uma concorrência entre recursos e competências (Sanchez e Heene, 1996; Hamel, 1994).

Partindo desses postulados de base, os trabalhos da teoria dos recursos exploram alguns temas comuns.

A vantagem competitiva pressupõe que as dotações de recursos das firmas sejam heterogêneas. Por causa dessa heterogeneidade de recursos, as firmas apresentam diferenças de performance econômica, algumas apresentando baixa lucratividade e outras apresentando lucratividade excepcionalmente alta em relação à média do mercado.

O controle por algumas firmas de recursos capazes de gerar uma performance superior pressupõe que a oferta desses recursos seja limitada. A raridade desses recursos provém seja de razões estruturais (limites físicos, naturais, legais ou temporais), seja de razões ligadas ao comportamento das firmas (a sua capacidade de desenvolver recursos únicos, de difícil imitação, a partir de insumos indiferenciados disponíveis no mercado). A restrição à oferta pode ser permanente ou temporária. O que atrai a atenção dos pesquisadores da teoria dos recursos são os recursos cuja oferta não pode ser aumentada a curto prazo. A inelasticidade da oferta desses recursos permite a obtenção de lucros acima da média do mercado (rendas ricardianas) enquanto durar a relativa raridade dos recursos e não existirem outras combinações de recursos capazes de produzir os mesmos bens ou bens substitutos.
Para que as rendas ricardianas não sejam erodidas, é necessário que elas sejam protegidas da ação dos concorrentes, evitando que estes tenham acesso aos mesmos recursos ou a recursos que produzam um resultado equivalente. Em resumo, é necessário que as condições de heterogeneidade sejam preservadas. Dois mecanismos que previnem a erosão das rendas são analisados: a imitabilidade imperfeita e a substituibilidade imperfeita (Peteraf, 1993). A imitabilidade imperfeita (imperfect imitability) dos recursos explica a dificuldade das firmas em identificar e reproduzir os recur- 
A diversidade dos mecanismos de isolamento reflete os interesses específicos e as abordagens particulares de um grande número de autores. Podemos, no entanto, notar que os autores que se identificam com a teoria dos recursos se concentram sobre os fatores e mecanismos que impedem a imitação de recursos específicos à firma, ao passo que, para os autores que se identificam com a economia industrial, as barreiras de entrada e saída (barreiras à mobilidade) são os principais elementos para explicar a diferença de performance entre as firmas.

Uma das condições necessárias para que recursos específicos sejam capazes de gerar rendas acima do nível médio de mercado é que sua transferência de uma firma a outra seja difícil ou até impossível. A mobilidade perfeita dos recursos eliminaria as rendas excepcionais, pois estas seriam incorporadas no sistema de equilíbrio geral de preços por meio do mercado de fatores.

Além dos fatores genéricos de produção utilizados pela firma - capital, maquinário, mão-de-obra, patentes - que são limitados por características físicas e direitos de propriedade bem definidos, o valor de uma grande parte dos recursos de uma firma não é capturado pelos preços de mercado e é essencialmente imóvel, devido a seu desenvolvimento ser atrelado às características específicas da firma. As razões para essa imperfeição dos mecanismos de mercado encontramse na natureza interdependente dos recursos e na dependência contextual das competências e do knowhow das firmas.

As firmas, em geral, empregam esses recursos em "feixes" caracterizados por relações de complementaridade e co-especialização (Teece, 1988). A dependência dos outros recursos limita a mobilidade de um recurso em particular, tornando as configurações individuais de recursos muito específicas às firmas que as desenvolveram (Black e Boal, 1994). Excetuada a aquisição da firma inteira, o mercado não dispõe de mecanismos para a transferência de sistemas (ou redes) de recursos, o que justifica o argumento da nãotransferência dos recursos.

A imperfeição dos mercados de fatores gera, também, a imposição de limites ex ante à concorrência.

Quadro 1 - Mecanismos de isolamento

\begin{tabular}{|c|c|}
\hline MECANISMO & REFERÊNCIA \\
\hline Recursos únicos/raros e imperfeitamente móveis & Wernerfelt, 1984; Barney, 1991 \\
\hline Talentos pessoais dos administradores & Penrose, $1959 / 1963$ \\
\hline Recursos não disponíveis no mercado & Barney, 1991 \\
\hline Competências fundamentais de difícil reprodução & Andrews, 1980; Hamel e Prahalad, 1994 \\
\hline Combinações únicas de experiências & Prahalad e Bettis, 1986; Spender, 1989 \\
\hline Culturas organizacionais, conhecimentos tácitos & Barney, 1986 \\
\hline Ativos invisíveis de imitação difícil & Itami e Roehl, 1987 \\
\hline Heurísticas e processos não facilmente imitáveis & Schoemaker, 1990 \\
\hline Economias ligadas ao tempo & Dierickx e Cool, 1989 \\
\hline Combinação de fatores de produção & Schumpeter, 1934 \\
\hline Capacidades gerenciais e de trabalho em equipe & Nelson e Winter, 1982 \\
\hline Dependência de trajeto (path dependency) & Arthur, 1989; Barney, 1991 \\
\hline Ambigüidade causal e racionalidade limitada & Simon, 1987; Lippman e Rumelt, 1982 \\
\hline Ativos idiossincráticos & Williamson, 1989 \\
\hline Ativos co-especializados (interconexão elevada) & Teece, 1988, 1994, 1997; Dierickx e Cool, 1989 \\
\hline Informação assimétrica, conhecimentos específicos & Barney, 1986; Winter, 1988 \\
\hline Irreversibilidade, engajamento de recursos & Ghemawat, 1991 \\
\hline Mercados imperfeitos de fatores & Barney, 1986; Rumelt, 1987 \\
\hline Barreiras de saída e "switching costs" & Porter, 1980 \\
\hline
\end{tabular}


Se os preços esperados dos recursos estratégicos são homogêneos e conhecidos (como suposto pela teoria microeconômica neoclássica) e se esses recursos podem ser transferidos de uma firma a outra, então, eles seriam avaliados como um fator de produção da mesma forma que os outros insumos, e a rentabilidade média do conjunto capital/recursos tenderia a se igualar à média de mercado. A existência de mercados imperfeitos de recursos é, assim, uma condição necessária para a existência de vantagem competitiva (Barney, 1986).

Os mercados de recursos não são apenas imperfeitos, eles são também incompletos: uma grande parte dos recursos não é negociável no mercado. Não podendo ser vendidos ou comprados, esses recursos devem forçosamente ser construídos no interior da firma. A sua acumulação interna garante, enfim, o caráter específico do conjunto de recursos de uma firma (Dierickx e Cool, 1989).

São, por fim, as falhas do mercado de recursos sua imperfeição e sua incompletude - que tornam possível a realização das rendas ricardianas e garantem a continuidade da heterogeneidade dos recursos.

A teoria dos recursos coloca em evidência as diferenças entre as firmas em função das diversidades entre suas bases de recursos e competências. Essas diferenças são desenvolvidas por meio das diversidades de escolhas e compromissos dos dirigentes das firmas (Selznick, 1957). Essas decisões não são tomadas por acaso, elas interagem fortemente com as decisões passadas condicionando as decisões presentes. A história é, dessa maneira, extremamente importante, engendrando irreversibilidades e impondo restrições (Arthur, 1989). O passado e o futuro estão, assim, intimamente ligados: “(...) not only may a strategic change lead to the need for a change in organizational structure (...), but the past, embedded in the current organizational structure and systems, itself determines the strategic opportunities of the present (...)" (Nanda, 1996).

Os trabalhos pioneiros de Penrose e da escola de design estratégico já haviam destacado a importância estratégica dos fatores internos à firma. Nessa visão, o papel da firma não é apenas a alocação de recursos escassos entre finalidades alternativas (Doz, 1996). Levando em conta a importância dos recursos para a performance competitiva, a gestão dos processos de acumulação, coordenação e difusão dos recursos passa a ser a função primordial da administração de empresas (Prahalad e Hamel, 1990).

A teoria dos recursos inverte, assim, o sentido da análise estratégica clássica, fundada em primeiro lugar na primazia do mercado (oportunidades e amea- ças na análise SWOT), para adotar recursos e competências (forças e fraquezas) como sendo a origem das estratégias bem-sucedidas.

A idéia de que os recursos devem guiar a estratégia mais fortemente que as restrições do ambiente externo (estrutura da indústria) está também no centro de diversas teorias sobre a diversificação das empresas. Nessas teorias, é o agrupamento de diversos conjuntos produto/mercado em torno de competências únicas que explica os esforços bem-sucedidos de diversificação (Barney, 1997; Collis, 1991; Grant, 1991).

Barney (1986) observa, ainda, que rendas excepcionais não podem ser concretizadas a partir da análise de oportunidades externas, pois as informações e as técnicas de análise dessas oportunidades estão acessíveis a todos os concorrentes. Por outro lado, as informações sobre os recursos da firma permanecem como suas propriedades exclusivas, protegidas pelos mecanismos de isolamento. Dessa forma, é a assimetria de informação relativa ao potencial dos recursos e das competências específicas da firma que deve guiar a estratégia, pois é a única fonte possível de vantagem competitiva.

Um balanço preliminar das contribuições da teoria dos recursos ancoradas na disciplina econômica mostra certos limites dessa abordagem. Foss (1997) identifica três limites maiores à teoria dos recursos: a) a ênfase na noção de equilíbrio; b) a ênfase em recursos discretos e c) o papel secundário atribuído ao ambiente.

A teoria dos recursos permanece, em geral, muito ligada às idéias neoclássicas de racionalidade, de comportamento econômico e de estabilidade e previsibilidade dos mercados (Foss, 1996, 1997). Esse foco na estabilidade é reconhecido por Barney (1997, p. 171): “(...) The resource-based view of the firm can help managers choose strategies to gain sustained competitive advantage only as long as the rules of the game in an industry remain relatively fixed. But, after a Schumpeterian revolution, what were weaknesses may become strengths and what were strengths may become weaknesses. (...) Thus, although sustained competitive advantages will not last forever, they are not competed away through imitation but can be displaced through revolutionary environmental changes (...)."

No entanto, quando tratamos de ambientes com alto grau de incerteza, ambigüidade e complexidade, como indústrias emergentes, fragmentadas ou em vias de internacionalização, as mudanças de contexto passam a ser ameaças concretas à sobrevivência das firmas. Nesse caso, temos situações de concor- 
rência schumpeteriana, que modificam a estrutura econômica de toda a indústria, por meio do processo de destruição criativa, da emergência de novas estratégias, de novas formas organizacionais e de novas competências (Schumpeter, 1982).

Um segundo limite aos trabalhos da teoria dos recursos, especialmente àqueles de natureza empírica, é o seu foco sobre recursos discretos, utilizando um modo de análise estático e ex post (Levinthal, 1995; Grant, 1991). Na maioria das vezes, por razões metodológicas, uma grande parte dos pesquisadores da teoria dos recursos se focaliza na existência ou não de recursos individuais em certas situações e em suas conseqüências em termos de performance. Essa ênfase em recursos individuais pode, no entanto, revelarse problemática, pois o caráter específico dos recursos encontra-se freqüentemente na sua configuração, isto é, no arranjo relativo entre vários recursos interdependentes (Penrose, 1959/1963).

Finalmente, ao privilegiar a determinação da estratégia "de dentro para fora" (inside-out), as abordagens centradas na teoria dos recursos descartam um papel predominante que pode ser atribuído às condições ambientais. Essa posição pode ser considerada um limite à teoria dos recursos: “(...) An error of omission that the resource perspective seems to be making is the obverse of some of the same mistakes it accuses the competitive strategy approach of making - it seems to be ascribing preeminence to the insideout perspective of strategy. Barney, for instance, asserted that the analysis of a firm's skills and capabilities will be of greater strategic value than the analysis of its competitive environment. However, as Wernerfelt (1984), Collis (1991) and Ghemawat (1991) pointed out, strategic analysis must recognize the duality between the resource-based and the product-based perspectives of the firm (...)" (Nanda, 1996, p. 103).

\section{PROCESSOS DE MERCADO: FOCALIZANDO MUDANÇA, INOVAÇÃO E DINÂMICA DA CONCORRÊNCIA}

Um importante grupo de contribuições às teorias sobre a vantagem competitiva concentra-se na dinâmica da empresa, dos mercados e da concorrência, enfatizando mais os processos de mudança e inovação do que as estruturas das indústrias (Porter, 1980) ou os arranjos estáveis de recursos. As origens desse movimento remontam aos trabalhos, em Viena, de Carl Menger, um dos fundadores da escola austríaca de economia, que inclui outros economistas importantes, como Von Mises, Hayek, Kirzner e
Schumpeter. As contribuições dos teóricos austríacos podem ser organizadas em quatro temas principais: a) os processos de mercado, b) o papel do empreendedor, c) a heterogeneidade das firmas e, finalmente, d) um conjunto de fatores não observáveis.

O papel do mercado na maior parte da literatura microeconômica neoclássica é o de um mecanismo equalizador, responsável pela redução de diferenças de rentabilidade entre as várias atividades econômicas possíveis. O mercado é a força niveladora que coordena as ações dos agentes econômicos individuais permitindo o atingimento do equilíbrio econômico por meio do mecanismo de preços como alocador universal de recursos. Os fenômenos econômicos que se desviam do equilíbrio podem ser produtos de acidentes temporários, corrigíveis pela ação livre do mecanismo de preços, que dirige a alocação de recursos, garantindo o equilíbrio geral do sistema econômico.

Constatando que a mudança, a inovação, o surgimento de novos concorrentes, os fenômenos de rendimento crescente e os resultados financeiros discrepantes da média do mercado são fenômenos comuns, alguns pesquisadores em economia partem em busca de um quadro conceitual capaz de explicar esses fenômenos não como aberrações de um modelo de equilíbrio, mas como ocorrências esperadas em um modelo que gera e preserva diferenças de performance. Para a escola austríaca, o mercado, longe de ser caracterizado pelo equilíbrio, é um processo de descoberta interativa que mobiliza informações divergentes e conhecimentos dispersos. As firmas obtêm lucros por meio da descoberta de oportunidades e da mobilização pioneira de recursos operada pelos empreendedores. Estes últimos, motivados pela perspectiva de lucros excepcionais, procuram sempre inovar, gerando novos arranjos econômicos e, conseqüentemente, causando o desequilíbrio do mercado. Tendo em vista que os concorrentes procuram imitar e suplantar os inovadores introduzindo outras inovações, o desequilíbrio do mercado passa a ser um estado permanente, e não um fenômeno transitório.

Kirzner descreve os processos de mercado destacando quatro aspectos fundamentais:

a) Competição: o que mantém os processos de mercado é a competição, não a concorrência perfeita em termos de ajustes de preços e quantidades, mas a competição entre firmas rivais que procuram aumentar os seus lucros oferecendo melhores produtos e serviços que aqueles existentes. A condição necessária para manter essa competição não é a existência de um grande número de rivais, mas sim a liberdade de fluxos de capitais, associada à 
inexistência de barreiras de entrada significativas nas indústrias.

b) Conhecimento e descoberta: segundo Hayek, o processo competitivo é caracterizado por um processo interativo de descoberta, em que novos conhecimentos são produzidos. Como os mercados podem assimilar e transmitir informações (preços, quantidades, recursos) somente sobre as práticas correntes, cabe ao empreendedor a tarefa de descobrir novas oportunidades de aplicação e gerar conhecimento relativo a essas oportunidades, conhecimento esse que alimentará o mercado e o processo de competição. Segundo Kirzner (1985, p. 131): “(...) The market, in other words, is not merely a process of search for information of the need of which men had previously been aware; it is a discovery procedure that tends to correct ignorance where the discoverers themselves were totally unaware that they indeed were ignorant (...)."

c) Incentivos e recompensas: as noções de lucro na teoria neoclássica e na escola austríaca não são as mesmas. Na versão ortodoxa, o lucro é o resultado da otimização do uso dos fatores de produção em oportunidades de aplicação conhecidas, dadas pela livre circulação de informação no mercado. Para a escola austríaca, lucros são resultantes da descoberta de novas oportunidades de produção e da criação de novas combinações de fatores de produção. A primeira noção de lucro tende a se confundir com o custo de oportunidade do capital, ao passo que a segunda representa as rendas do empreendedor, obtidas por meio da descoberta de novas fronteiras de produtividade e do estabelecimento de situações de monopólio temporário. “(...) the availability of pure entrepreneurial profit has the function not of outweighting the cost associated with withdrawing inputs from alternative uses, but of alerting decision makers to the present error of committing factors to uses less valuable to the markets than others waiting to be served (...)" (Kirzner, 1985, p. 133). d) Os preços de mercado: em vez de se aproximarem dos preços de equilíbrio, para a escola austríaca, os preços traduzem o valor relativo das descobertas feitas pelos empreendedores. Eles sinalizam, assim, oportunidades de lucros excepcionais, ou seja, de estabelecimento de rendas de empreendimento (Rumelt, 1987), que, na prática, correspondem a monopólios transitórios. A descoberta e exploração dessas oportunidades de pioneirismo é o motor dos processos de mercado como geração de conhecimento.

É nos trabalhos de Schumpeter que o empreendedor adquire sua expressão mais plena. O empreendedor é, segundo esse autor, o responsável pela introdução de inovações capazes de melhor satisfazer as demandas do mercado. Segundo ele, o desenvolvimento econômico ocorre quando as firmas desenvolvem inovações perturbando o equilíbrio de forças competitivas anteriormente prevalecentes. Para Schumpeter, é esse processo de "destruição criadora", a renovação constante de produtos, processos e formas organizacionais, que permite o estabelecimento temporário de rendas do empreendedor e que impede o mercado de manter uma posição de equilíbrio.

O papel dos empreendedores é descobrir novas oportunidades de produção, isto é, métodos de produção mais eficientes e produtos mais eficazes em termos de resultados finais para os consumidores. Isso implica a utilização simultânea de dois tipos de conhecimento: a) métodos científicos e mobilização de conhecimentos explícitos e b) informações circunstanciais e contextuais, comumente associadas a formas tácitas de conhecimento das especificidades locais.

Cabe lembrar, ainda, que as funções do empreendedor não estão apenas ligadas à inovação radical mas também à rápida capacidade de imitação dos concorrentes, uma vez que ambos os comportamentos contribuem para a maior eficiência do sistema econômico como um todo.

A escola austríaca considera a firma como uma entidade na qual a história e as características individu-

\begin{tabular}{|l|l|l|}
\hline \multicolumn{2}{|l|}{ Quadro 2 - Diferenças entre a escola de organização industrial e a escola austríaca } \\
\hline & ORGANIZAÇÃO INDUSTRIAL & ESCOLA AUSTRÍACA \\
\hline OBJETIVO ESTRATÉGICO & Restrição de forças competitivas & Descoberta empreendedora \\
\hline MERCADO & Equilíbrio & Desequilíbrio \\
\hline MODELO DE RENTABILIDADE & Regularidades empíricas & Diversidade \\
\hline FATORES DE SUCESSO & Variáveis observáveis & Variáveis inobserváveis \\
\hline Fonte: Jacobson (1992, p. 7$).$ & \\
\hline
\end{tabular}


ais tornam muito difícil a imitação perfeita pelos concorrentes. A natureza da competição entre firmas sugere que nenhuma estratégia que possa ser livremente replicada pode assegurar taxas de rentabilidade acima da média do mercado. Nessas condições, para que uma firma possa manter uma rentabilidade elevada, ela deve basear-se em estratégias de inovação permanente, derivadas de elementos de difícil imitação por parte dos concorrentes. Para atingir esse objetivo, os teóricos da escola austríaca ressaltam a importância dos "fatores inobserváveis". Esses fatores de natureza subjetiva seriam justamente aqueles capazes de escapar à dinâmica da imitação do mercado, sendo, assim, responsáveis pelo estabelecimento da vantagem competitiva.

trutura da indústria deve ser vista como o resultado endógeno das diferenças de performance das firmas no decorrer do tempo em vez de ser considerada um fator determinante da performance destas últimas.

\section{O MODELO DE CAPACIDADES DINÂMICAS (DYNAMIC CAPABILITIES): INOVAÇÃO E RECONFIGURAÇÕES}

Um segundo grupo de contribuições elabora as idéias colocadas nas teorias dos processos de mercado e na teoria dos recursos tentando formular uma teoria da formação das competências organizacionais em ambientes de alta complexidade e mudança constante.

Em primeiro lugar, essa síntese teórica pretende acentuar os aspectos de co-evolução entre ambientes concorrenciais crescentemente complexos e as capacidades e os recursos das firmas (Amit e Schoemaker, 1993; Gorman et al., 1996; Teece et al., 1997). Por outro lado, essa síntese pretende estudar mais detalhadamente os mecanismos e processos organizacionais ca-

Essa proposição fundamenta-se na constatação de que certas empresas conseguem sustentar uma performance superior apesar dos contínuos esforços de imitação dos concorrentes no tocante às suas estratégias, produtos, métodos de produção e esquemas de distribuição. A diferença de performance é, então, atribuída a fatores inobserváveis, invisíveis, que se escondem por trás dos fatores objetivamente mensuráveis dos processos de produção.

As premissas dos pesquisadores da escola austríaca em relação à vantagem competitiva são fundamentalmente distintas das adotadas pelos teóricos da organização industrial. O Quadro 2 compara essas duas abordagens.

Alguns pesquisadores vinculados à escola austríaca colocam em questão a estrutura central do modelo da organização industrial. Para Hill e Deeds, o modelo da análise estrutural da indústria identifica erroneamente a estrutura da indústria como o fator causal mais importante na determinação da natureza da concorrência e dos níveis de rentabilidade (Hill e Deeds, 1996). Para esses autores, a natureza da competição entre as firmas é independente da estrutura da indústria, sendo um dado característico do sistema capitalista. Por serem processos independentes, são a dinâmica competitiva e a descoberta das inovações que influenciam os níveis de performance econômica das firmas. No modelo proposto por esses autores, a es- pazes de explicar a acumulação e a configuração das bases de recursos das firmas (Dierickx e Cool, 1989; Teece et al., 1997; Sanchez e Heene, 1996).

Partindo da concepção geral da firma como um conjunto de recursos, esse modelo procura estudar as relações entre os processos de decisão, as ações empreendidas e as suas conseqüências gerenciais, em termos da formação, conservação e destruição de recursos.

Hogarth e Michaud (1991) identificam quatro fontes diferentes da vantagem competitiva das firmas, cada uma fundada sobre tipos específicos de recursos:

a) O acesso privilegiado a recursos únicos, em que as rendas são derivadas da propriedade ou do acesso a recursos raros e valiosos. Concessões, patentes ou localizações geográficas privilegiadas são exemplos de recursos desse tipo. Nesse caso, as rendas derivam diretamente dos direitos de propriedade ou do acesso aos recursos. É o caso das rendas ricardianas por excelência.

b) A capacidade de transformação dos fatores de produção em produtos vendáveis no mercado. Nesse caso, a vantagem competitiva deriva de capacidades ou processos distintivos acumulados no decorrer do tempo. A vantagem competitiva se exprime na capacidade de empregar métodos operacionais mais eficientes que os empregados pelas firmas con- 
correntes. No entanto, esses recursos e essas capacidades são fixos, e a firma não é capaz de modificálos, embora a vantagem competitiva derive deles.

c) A alavancagem de recursos e capacidades. Nesse estágio, a firma é capaz de agir deliberadamente para renovar seu estoque de recursos e competências, aperfeiçoando e recombinando os recursos existentes com o objetivo de criar novos produtos e mercados.

d) A regeneração de recursos e capacidades. Nesse último estágio, as firmas devem ser capaz de criar um fluxo contínuo de inovações graças ao desenvolvimento de competências de ordem superior, ligadas à própria capacidade de gerar novas competências e recursos. Trata-se, nesse caso, de construir um sistema capaz de gerar uma série continuada de inovações a partir da reconfiguração repetida da base de recursos da firma.

Os primeiros trabalhos na linha da teoria dos recursos concentraram-se, como analisamos anteriormente, em recursos discretos estáveis e cuja identificação era relativamente simples e direta: os recursos previstos nos itens "a" e "b" da classificação de Hogarth e Michaud. Mesmo que esses recursos sejam capazes de explicar a vantagem competitiva das firmas no longo prazo, é preciso levar em consideração, segundo essa corrente, os itens "c" e "d" da classificação anterior. As capacidades e os recursos previstos nesse tipo de recursos são essencialmente dinâmicos e pautam-se por um processo de renovação contínua: “(...) The term 'dynamic' refers to the capacity to renew competences so as to achieve congruence with the changing business environment (...) The term 'capabilities' emphasizes the key role of strategic management in appropriately adapting, integrating, and reconfiguring internal and external organizational skills, resources, and functional competences to match the requirements of a changing environment (...)" (Teece et al., 1997, p. 515).

A dependência de recursos e capacidades estáticas pode, então, gerar riscos para as firmas, como os problemas advindos da superespecialização (Miller, 1992), e rigidez (core rigidities) em suas competências e recursos (Leonard-Barton, 1992, 1995).

Nos trabalhos da teoria dos recursos, os recursos e as capacidades são tratados essencialmente como variáveis de estoque, como dados mais ou menos fixos, o que é uma condição crítica para a realização das rendas ricardianas. Na abordagem das capacidades dinâmicas, mais importante que o estoque atual de recursos é a capacidade de acumular e combinar novos recursos em novas configurações capazes de gerar fontes adicionais de rendas.

\section{Com a alteração das condições ambientais,} mudam também os recursos essenciais para garantir a sobrevivência e a performance econômica diferenciada das firmas. É a antecipação dessas transformações nos portfólios de recursos que garante às empresas a possibilidade de continuação da vantagem competitiva.

A posição atual dos recursos é, dessa forma, o resultado das ações e decisões (deliberadas ou acidentais) tomadas pelos integrantes da firma no exercício de suas tarefas e rotinas cotidianas. Por essa razão, para poder compreender o sentido da acumulação de recursos, é necessário entender as rotinas e os processos organizacionais. O ponto central dessa análise é justamente o conjunto de processos administrativos (rotinas, atividades, culturas, prioridades) que influenciam a produção de ativos tangíveis e intangíveis nas firmas. Os processos aqui referidos são: “(...) the way things are done in the firm, or what might be referred to as its routines, or patterns, of current practice and learning (...)" (Teece et al., 1997, p. 518).

Esses processos administrativos e organizacionais cumprem três funções básicas:

a) Uma função de coordenação/integração (conceito estático): visando a coordenar o uso interno e externo dos recursos da firma.

b) Uma função de aprendizagem (conceito dinâmico): focalizando os processos pelos quais a repetição da experimentação possibilita a utilização mais eficaz dos recursos.

c) Uma função de reconfiguração (conceito transformacional): dedicada aos mecanismos de antecipação da necessidade de novas competências e aos métodos de reconfiguração dos recursos que permitirão a continuidade de performances superiores. Os autores que trabalham dentro da corrente das capacidades dinâmicas tentam construir um edifício teórico com base em premissas mais realistas sobre as relações entre as estruturas cognitivas dos agentes 
econômicos e as decisões estratégicas das firmas (Prahalad e Bettis, 1986; Barr, 1992; Gorman et al., 1996). Dessa maneira, a noção de capacidades dinâmicas: "(...) extends the resource-based view of the firm as a collection of asset stocks and flows (...) by explicitly incorporating (1) managerial cognition that affects what kinds of asset stocks and flows the firm will try to achieve, (2) managers' coordination ability in deploying resources and managing asset flows, and (3) managers' abilities to manage knowledge in processes for building and leveraging competences (...)" (Sanchez e Heene, 1996, p. 15).

Em resumo, o enfoque privilegiado nos processos organizacionais permite a criação de uma teoria estratégica mais flexível do que as visões economicistas nas quais os recursos são vistos como elementos estáveis, identificados ex post.

Os desenvolvimentos teóricos que levaram a uma teoria dinâmica das capacidades retomam a análise dos fatores ambientais, que, na teoria dos recursos, ficaram em segundo plano como um dos fatores determinantes no processo de decisão estratégica. A concorrência entre as firmas, tradicionalmente concentrada na análise de mercados e produtos, passa a ser analisada em termos de recursos únicos ou raros que derivam de processos organizacionais específicos às firmas. A concorrência fundada sobre as competências das firmas (competence-based competition) sobrepõe-se à noção tradicional de concorrências entre produtos e serviços (Prahalad e Hamel, 1990; Stalk et al., 1992).

“(...) The 'competitive locus' of competence-based competition is a contest for acquisition of skills. Competition in product markets is 'merely a superficial expression' of the underlying competition over competencies (...)" (Rumelt, 1994).

Essa abertura para o ambiente permite a consideração da evolução dinâmica das dotações de recursos das firmas sem prejuízo à importância dos estoques de recursos específicos de cada firma.

As mudanças nas condições ambientais freqüentemente exigem das empresas uma regeneração da sua base de recursos e competências. Com a alteração das condições ambientais, mudam também os recursos essenciais para garantir a sobrevivência e a performance econômica diferenciada das firmas. É a antecipação dessas transformações nos portfólios de recursos que garante às empresas a possibilidade de continuação da vantagem competitiva (Amit e Schoemaker, 1993).

Finalmente, os autores que examinam os ambientes hipercompetitivos e turbulentos destacaram a necessidade de continuamente redefinir as bases de recursos das firmas, reforçando suas competências (competence strengthening) a fim de desenvolver recursos estratégicos mais amplos (meta-recursos) capazes de permitir a rápida modificação da base de recursos da firma (Chakravarthy, 1997; D’Aveni e Gunther, 1994).

A teoria das capacidades dinâmicas aceita as premissas de que: a) nem todas as competências são igualmente importantes para a vantagem competitiva e b) uma dada firma só pode se destacar em um número relativamente restrito de competências. Essas competências são, assim, definidas como competências centrais (core competencies): “(...) (1) core competences are competences that 'span' across businesses and products within a corporation. They support several products or businesses. (2) Competences have 'temporal dominance' over products in that they evolve more slowly than the products they make possible. (3) Competences arise through the 'collective learning' of the firm, especially through the coordination of diverse production skills and the integration of multiple streams of technologies. (...)" (Rumelt, 1994).

Os processos de aquisição e estruturação do conhecimento em nível organizacional estão no centro do processo de configuração de recursos (Henderson e Clark, 1990; Leonard-Barton, 1992) e, por essa razão, a aprendizagem organizacional e os conhecimentos tácitos têm um papel determinante na identificação e no desenvolvimento das competências centrais.

A importância do conhecimento da informação e da tecnologia para a performance das empresas tem sido amplamente reconhecida por diversas correntes teóricas. Para os estudiosos da teoria dos recursos e para os que defendem uma visão dinâmica das capacidades organizacionais, os recursos e as capacidades da firma são resultado de um processo de aprendizagem por experiência (learning by doing), que constitui o repertório de ações coletivas disponíveis para as firmas. As competências centrais traduzem, dessa maneira, os conhecimentos tácitos da firma obtidos com a aplicação de seus recursos específicos (Winter, 1987; Spender e Grant, 1996).

Assim, as firmas são descritas como locais de integração de conhecimento (Grant, 1996), de criação de conhecimento (Nonaka, 1994) ou de proteção do conhecimento (Liebeskind, 1996), o que coloca aos pesquisadores desafios metodológicos importantes (Godfrey e Hill, 1995).

A corrente de capacidades dinâmicas reconhece as restrições impostas pela base atual de recursos e pela trajetória histórica da firma. No entanto, diante da incerteza, da instabilidade do contexto concorrencial e da inevitabilidade, em longo prazo, da de- 
gradação da base de recursos, a corrente de capacidades dinâmicas procura fornecer uma explicação de como as firmas podem agir para reconfigurar, proativa ou reativamente, a sua base de recursos.
Dessa forma: “(...) indeed, if control over scarce resources is the source of economic profits, then it follows that such issues as skill acquisition, the management of knowledge and know-how, and

\begin{tabular}{|c|c|c|c|c|}
\hline DIMENSÕES & $\begin{array}{l}\text { ORGANIZAÇÃO } \\
\text { INDUSTRIAL }\end{array}$ & RECURSOS & $\begin{array}{l}\text { PROCESSOS DE } \\
\text { MERCADO }\end{array}$ & $\begin{array}{l}\text { CAPACIDADES } \\
\text { DINÂMICAS }\end{array}$ \\
\hline $\begin{array}{l}\text { Unidade de } \\
\text { análise }\end{array}$ & Indústria & $\begin{array}{l}\text { Estoques de recursos } \\
\text { e competências } \\
\text { específicas }\end{array}$ & $\begin{array}{l}\text { Dinâmica do mercado, } \\
\text { ciclos de criação e } \\
\text { destruição, inovação } \\
\text { imitação e seleção }\end{array}$ & $\begin{array}{l}\text { Processos e rotinas } \\
\text { organizacionais; fluxos de } \\
\text { recursos e competências } \\
\text { específicas }\end{array}$ \\
\hline $\begin{array}{l}\text { Concepção da } \\
\text { firma }\end{array}$ & $\begin{array}{l}\text { Função técnica de } \\
\text { produção } \\
\text { Conjunto de atividades } \\
\text { complementares }\end{array}$ & $\begin{array}{l}\text { Conjunto estável de } \\
\text { recursos, } \\
\text { competências e } \\
\text { capacidades }\end{array}$ & $\begin{array}{l}\text { Empreendedora: } \\
\text { produção de } \\
\text { inovações, criação de } \\
\text { conhecimento }\end{array}$ & $\begin{array}{l}\text { Conjunto evolutivo de } \\
\text { recursos, competências e } \\
\text { capacidades }\end{array}$ \\
\hline $\begin{array}{l}\text { Natureza da } \\
\text { vantagem } \\
\text { competitiva }\end{array}$ & $\begin{array}{l}\text { Sustentável, fundada } \\
\text { no exercício de } \\
\text { situações de quase- } \\
\text { monopólio }\end{array}$ & $\begin{array}{l}\text { Sustentável, fundada } \\
\text { sobre recursos } \\
\text { estáveis } \\
\text { Rendas ricardianas }\end{array}$ & $\begin{array}{l}\text { Transitória e cíclica, } \\
\text { fundada em rendas de } \\
\text { empreendedor }\end{array}$ & $\begin{array}{l}\text { Sustentável, fundada sobre } \\
\text { recursos em evolução } \\
\text { Rendas ricardianas e de } \\
\text { empreendedor }\end{array}$ \\
\hline $\begin{array}{l}\text { Fonte de } \\
\text { vantagem } \\
\text { competitiva }\end{array}$ & $\begin{array}{l}\text { Atratividade e } \\
\text { posicionamento da } \\
\text { firma na indústria }\end{array}$ & $\begin{array}{l}\text { Acesso privilegiado a } \\
\text { recursos únicos de } \\
\text { difícil imitação }\end{array}$ & $\begin{array}{l}\text { Inovação e } \\
\text { "destruição criadora" }\end{array}$ & $\begin{array}{l}\text { Rotinas e processos } \\
\text { organizacionais capazes } \\
\text { de regenerar a base de } \\
\text { recursos da firma }\end{array}$ \\
\hline Estratégia & $\begin{array}{l}\text { Orientada para o } \\
\text { conteúdo } \\
\text { Abordagem racional } \\
\text { "de fora para dentro" } \\
\text { (outside-in) } \\
\text { Procura de indústrias } \\
\text { atrativas, busca do } \\
\text { posicionamento ideal } \\
\text { na indústria e defesa } \\
\text { dessa posição pela } \\
\text { construção de barreiras } \\
\text { à concorrência }\end{array}$ & $\begin{array}{l}\text { Orientada para o } \\
\text { conteúdo } \\
\text { Abordagem racional } \\
\text { "de dentro para fora" } \\
\text { (inside-out) } \\
\text { Desenvolvimento e } \\
\text { exploração de } \\
\text { competências } \\
\text { existentes }\end{array}$ & $\begin{array}{l}\text { Orientada para o } \\
\text { processo } \\
\text { Procura contínua de } \\
\text { oportunidades de } \\
\text { inovação } \\
\text { Esforços de imitação } \\
\text { das inovações bem- } \\
\text { sucedidas }\end{array}$ & $\begin{array}{l}\text { Orientada para o processo } \\
\text { e o conteúdo } \\
\text { Interação entre } \\
\text { competências e } \\
\text { oportunidades do } \\
\text { mercado } \\
\text { Reconfiguração de } \\
\text { competências e know-how } \\
\text { Racionalidade limitada, } \\
\text { incerteza, complexidade e } \\
\text { conflito }\end{array}$ \\
\hline Fundadores & $\begin{array}{l}\text { E. Mason } \\
\text { J. S. Bain }\end{array}$ & $\begin{array}{l}\text { P. Selznick } \\
\text { E. Penrose } \\
\text { K. Andrews }\end{array}$ & $\begin{array}{l}\text { L. Mises } \\
\text { F. Hayek } \\
\text { J. Schumpeter }\end{array}$ & $\begin{array}{l}\text { D. Teece } \\
\text { R. Nelson } \\
\text { S. Winter }\end{array}$ \\
\hline $\begin{array}{l}\text { Autores } \\
\text { representativos }\end{array}$ & $\begin{array}{l}\text { M. Porter } \\
\text { P. Ghemawat } \\
\text { C. Shapiro }\end{array}$ & $\begin{array}{l}\text { R. Rumelt } \\
\text { B. Wernerfelt } \\
\text { J. B. Barney } \\
\text { M. Peteraf }\end{array}$ & $\begin{array}{l}\text { R. Jacobson } \\
\text { R. D'Aveni }\end{array}$ & $\begin{array}{l}\text { D. Teece, G. Pisano e A. } \\
\text { Shuen } \\
\text { C. K. Prahalad e G. Hamel } \\
\text { I. Dierickx e K. Cool } \\
\text { R. Amit e P. Shoemaker } \\
\text { R. Sanchez, A. Heene e H. } \\
\text { Thomas }\end{array}$ \\
\hline
\end{tabular}


learning become fundamental strategic issues (...)" (Teece et al., 1997, p. 514).

\section{OS MODELOS EXPLICATIVOS DA VANTAGEM COMPETITIVA: UMA SÍNTESE COMPARATIVA}

Este artigo identificou quatro grandes modelos explicativos da vantagem competitiva, cada um deles com suas premissas variáveis e relações explicativas focalizadas em níveis de análise distintos, conforme demonstrado no Quadro 3.

A comparação dessas quatro abordagens teóricas permite-nos retornar à questão inicial deste artigo, a convergência entre teoria organizacional e análise estratégica. Podemos observar que se, nas teorias da organização industrial, dos recursos e dos processos de mercado, a estratégia permanece um tópico relativamente distante da análise organizacional, quando abordamos a questão da vantagem competitiva sob o ponto de vista da teoria das capacidades dinâmicas, abre-se uma significativa possibilidade de convergência entre a estratégia e a teoria. Essa convergência propicia espaços para que as disciplinas possam se enriquecer mutuamente, mas, por outro lado, torna o trabalho de pesquisa mais e mais complexo, dado o aumento das variáveis que devem ser levadas em consideração.

O que determinará a viabilidade em longo prazo deste trabalho interdisciplinar será justamente a sua capacidade de explicar os diversos aspectos das realidades sociais e econômicas. Nesse sentido, o que a análise interdisciplinar perde em simplicidade ela ganha em poder explicativo. $O$

REFERÊNCIAS BIBLIOGRÁFICAS

AMIT, R., SCHOEMAKER, P. Strategic assets and organizational rent. Strategic Management Journal, v. 14, n. 1, p. 33-46, Jan. 1993.

ANDREWS, K. R. The concept of corporate strategy. New York: Richard D. Irwin, 1980.

ARTHUR, W. B. Competing technologies, increasing returns, and lock-in by historical events. The Economic Journal, v. 99, n. 394, p. 116-131, Mar. 1989.

BARNEY, J. B. Strategic factor markets: expectations, luck, and business strategy. Management Science, v. 32, n. 10 , p. 1231-1241, 1986.

BARNEY, J. B. Firm resources and sustained competitive advantage. Journal of Management, v. 17, n. 1, p. 99120, 1991.

BARNEY, J. B. Gaining and sustaining competitive advantage. Reading, MA : Addison-Wesley Publishing Company, 1997.

BARR, P. S. et al. Cognitive change, strategic action, and organizational renewal. Strategic Management Journal, v. 13 , p. 15-36, Summer 1992. Special issue.

BLACK, J. A., BOAL, K. B. Strategic resources: traits, configurations and paths to sustainable competitive advantage. Strategic Management Journal, v. 15, p. 131 148, Summer 1994. Special issue.

CHAKRAVARTHY, B. A new strategy framework for coping with turbulence. Sloan Management Review, v. 38, n. 2, p. 69-82, Winter 1997.

COASE, R. H. La nature de la firme. Revue Française d'Economie, v. 2, n. 1, p. 133-156, 1987.
COLLIS, D. J. A resource-based analysis of global competition: the case of the bearings industry. Strategic Management Journal, v. 12, p. 49-68, Summer 1991. Special issue.

COLLIS, D. J. Organizational capability as a source of profit. In: MOINGEON, B., EDMONDSON, A. Organizational learning and competitive advantage. London: Sage Publications, 1996. V. 1, p. 229.

CORIAT, B., WEINSTEIN, O. Les nouvelles théories de l'entreprise. Paris : Le Livre de Poche, 1995.

D'AVENI, R. A., GUNTHER, R. Hypercompetition: managing the dynamics of strategic maneuvering. New York: Free Press, 1994

DIERICKX, I., COOL, K. Asset stock accumulation and sustainability of competitive advantage. Management Science, v. 35, n. 12, p. 1504-1513, 1989.

DOZ, Y. Managing core competency for corporate renewal: towards a managerial theory of core competencies. In: DOSI, G., MALERBA, F. Organization strategy in the evolution of the enterprise. New York : MacMillan Press, 1996. p. $155-178$.

FAMA, E. F. Agency problems and the theory of the firm. Journal of Political Economy, v. 88, n. 2, p. 288-307, 1980

FOSS, N. J. Research in strategy, economics, and Michael Porter. Journal of Management Studies, v. 33, n. 1, p. 124, 1996.

FOSS, N. J. Resources and strategy: a brief overview of themes and contributions. In: FOSS, N. J. Resources, firms and strategies: a reader in the resource-based perspective. New York : Oxford University Press, 1997. p. 3-18.
GHEMAWAT, P. Sustainable advantage. Harvard Business Review, v. 64, n. 5, p. 53-58, Sep./Oct. 1986.

GHEMAWAT, P. Commitment: the dynamic of strategy. New York: Free Press, 1991.

GODFREY, P. C., HILL, C. W. L. The problem of unobservables in strategic management research. Strategic Management Journal, v. 16, n. 7, p. 519533, Oct. 1995.

GORMAN, P. et al. Industry dynamics in competencebased competition. In: SANCHEZ, R., HEENE, A. THOMAS, H. Dynamics of competence-based competition: theory and practice. Oxford: Pergamon, 1996. p. $85-98$

GRANT, R. M. The resource-based theory of competitive advantage: implications for strategy formulation California Management Review, p. 114-135, Spring 1991.

GRANT, R. M. Prospering in dynamically-competitive environments: organizational capability as knowledge integration. Organizational Science, v. 7 , n. 4, p. 375397, 1996.

HALL, R. The strategic analysis of intangible resources. Strategic Management Journal, v. 13, n. 2, p. 135-144, Feb. 1992.

HAMEL, G. The concept of core competence. In: HAMEL, G., HEENE, A. Competence-based competition. Chichester : John Wiley \& Sons, 1994. p. 11-33.

HAMEL, G. The next round of competitive challenges for industry. EFDM Forum, v. 2, n. 1, 1995.

HAMEL, G., PRAHALAD, C. K. Competing for the future. Harvard Business Review, v. 72, n. 4, p. 122-128, July/ Aug. 1994. 
HENDERSON, R. M., CLARK, K. B. Architectural innovation: the reconfiguration of existing product technologies and the failure of established firms. Administrative Science Quarterly, v. 35, n. 1, p. 9-30, Mar. 1990.

HILL, C. W. L., DEEDS, D. L. The importance of industry structure for the determination of firm profitability: a newAustrian perspective. Journal of Management Studies, v. 33 , n. 4 , p. $429-451,1996$.

HOGARTH, R., MICHAUD, C. Longevity of business firms: a four-stage framework. Fontainebleau : INSEAD, 1991.

ITAMI, H., ROEHL, T. Mobilizing invisible assets. Cambridge, MA : Harvard University Press, 1987.

JACOBSON, R. The "Austrian" School of Strategy. Academy of Management Review, v. 17, n. 4, p. 782807, 1992.

JENSEN, M. C., MECKLING, W. H. Theory of the firm: managerial behavior, agency costs and ownership behavior. Journal of Financial Economics, v. 3, p. 305360, 1976.

KIRZNER, I. M. Discovery and the capitalist process. Chicago : The University of Chicago Press, 1985.

LEONARD-BARTON, D. Core capabilities and core rigidities: a paradox in managing new product development. Strategic Management Journal, v. 13, p. 111-125, Summer 1992. Special issue.

LEONARD-BARTON, D. Wellsprings of knowledge: building and sustaining the sources of innovation. Boston : Harvard Business School Press, 1995

LEVINTHAL, D. A. Strategic management and the exploration of diversity. In: MONTGOMERY, C. A. Resource-based and evolutionary theories of the firm. towards a synthesis. Boston : Kluwer Academic Publishers, 1995. p. 19-41.

LIEBESKIND, J. P. Knowledge, strategy and the theory of the firm. Strategic Management Journal, v. 17, p. 93107, Winter 1996. Special issue.

LIPPMAN, S. A., RUMELT, R. P. Uncertain imitability: an analysis of interfirm differences in efficiency under competition. The Bell Journal of Economics, v. 13, p. 418438, 1982.

MAHONEY, J. T., PANDIAN, J. R. The resource-based view within the conversation of strategic management. Strategic Management Journal, v. 13, n. 5, p. 363-380, June 1992.

MILLER, D. The generic strategy trap. Journal of Business Strategy, p. 37-41, Jan./Feb. 1992.

MINTZBERG, H. The fall and rise of strategic planning. Harvard Business Review, v. 72, n. 1, p. 107-114, Jan./ Feb. 1994.

NANDA, A. Resources, capabilities and competencies. In: MOINGEON, B., EDMONDSON, A. Organizational learning and competitive advantage. London: Sage Publications, 1996. p. 229.
NELSON, R. R. Why do firms differ, and how does it matter. Strategic Management Journal, v. 12, p. 61-74, Winter 1991. Special issue.

NELSON, R., WINTER, S. An evolutionary the ory of economic change. Cambridge, MA : Belknap Press, 1982.

NONAKA, I. A dynamic theory of organizational knowledge creation. Organizational Science, v. 5, n. 1, p. 14-37, 1994.

PENROSE, E. T. Facteurs, conditions et mécanismes de la croissance de l'entreprise. Neuilly-sur-Seine : Editions Hommes et Techniques, 1959/1963.

PETERAF, M. A. The cornerstones of competitive advantage: a resource-based view. Strategic Management Journal, v. 14, n. 3, p. 179-191, Mar. 1993.

PORTER, M. E. Competitive strategy. New York : Free Press, 1980

PORTER, M. E. Towards a dynamic theory of strategy. Strategic Management Journal, v. 12, p. 95-117, Winter 1991. Special issue.

PORTER, M. E. What is strategy? Harvard Business Review, v. 74, n. 6, p. 61-78, Nov./Dec. 1996.

PRAHALAD, C. K., BETTIS, R. A. The dominant logic: a new linkage between diversity and performance. Strategic Management Journal, v. 7, n. 6, p. 485-501, Nov./Dec. 1986.

PRAHALAD, C. K., HAMEL, G. The core competence of the corporation. Harvard Business Review, v. 68, n. 3, p. 79-91, May/June 1990.

REED, R., DEFILLIPPI, R. J. Causal ambiguity, barriers to imitation, and sustainable competitive advantage. Academy of Management Review, v. 15, n. 1, p. 88-102, 1990.

RUMELT, R. P. Toward a strategic theory of the firm. In: LAMB, R. Competitive strategic management. Englewood Cliffs, NJ : Prentice-Hall, 1984.

RUMELT, R. P. Theory, strategy and the entrepreneurship. In: TEECE, D. J. The competitive challenge: strategies for industrial innovation and renewal. Cambridge, MA : Harper and Row, 1987. p. 137-158.

RUMELT, R. P. How much does industry matter? Strategic Management Journal, v. 12, n. 3, p. 167-185, Mar. 1991.

RUMELT, R. P. Foreword. In: HAMEL, G., HEENE, A. Competence-based competition. Chichester, UK : John Wiley \& Sons, 1994. p. XV-XIX.

SANCHEZ, R., HEENE, A. Introduction: towards the theory and practice of competence-based competition. In: SANCHEZ, R., HEENE, A., THOMAS, H. Dynamics of competence-based competition: theory and practice in the new strategic management. Oxford : Pergamon, 1996. p. 1-35.
SCHOEMAKER, P. J. H. Strategy, complexity and economic rent. Management Science, v. 36, n. 10, p. 1178-1192, 1990.

SCHUMPETER, J. A. The Theory of Economic Development: an inquiry into profits, capital, credit, interest and the business cycle. Cambridge, MA : Harvard University Press, 1934/1955.

SCHUMPETER, J. A. Capitalisme, socialisme et démocratie. Paris : Editions Payot, 1982.

SELZNICK, P. Leadership and administration. New York : Harper \& Row, 1957.

SHAPIRO, C. The theory of business strategy. RAND Journal of Economics, v. 20, n. 1, p. 125-137, 1989.

SIMON, H. A. Making management decisions: the role of intuition and emotion. Academy of Management Executive, p. 57-64, Feb. 1987.

SPENDER, J. C. Industry recipes. Oxford : BasilBlackwell, 1989.

SPENDER, J. C., GRANT, R. M. Knowledge and the firm: overview. Strategic Management Journal, v. 17, p. 5-9, Winter 1996. Special issue.

STALK, G. et al. Competing on capabilities: the new rules of corporate strategy. Harvard Business Review, v. 70, n. 2, p. 57-69, Mar./Apr. 1992.

TEECE, D. J. Economic analysis and strategic management. California Management Review, v. 26, n. 3, p. 87-110, Spring 1984.

TEECE, D. J. Profiting from technological innovation: implications for integration, collaboration, licensing and public policy. In: TUSHMAN, M. L., MOORE, W. L. Readings in the management of innovation. s.l. : HarperBusinness, 1988. p. $621-647$.

TEECE, D. J. History of strategic management. In: RUMELT, R. P., SCHENDEL, D. E., TEECE, D. J. Fundamental issues in strategy: a research agenda. Cambridge : Harvard Business Press, 1994.

TEECE, D. J. et al. Dynamic capabilities and strategic management. Strategic Management Journal, v. 18, n. 7 , p. 509-533, Aug. 1997.

WERNERFELT, B. A resource-based view of the firm Strategic Management Journal, v. 5, p. 171-180, 1984.

WILLIAMSON, O. E. Market and hierarchies: analysis and antitrust implications. New York : Free Press, 1975.

WILLIAMSON, 0. E. Transaction cost economics. In: SCHMALENSEE, R., WILLIG, R. D. Handbook of industrial organization. s.I. : Elsevier Science Publishers, 1989. v. 1, p. 136-182.

WINTER, S. G. Knowledge and competence as strategic assets. In: TEECE, D. J. The competitive challenge: strategies for industrial innovation and renewal. New York: Harper \& Row, 1987. p. 159-184.

WINTER, S. On Coase, competence, and the corporation. Journal of Law, Economics, and Organization, v. 4, p. 163180, 1988. 